\title{
No longer novel: The association of a dilated coronary sinus with left ventricular inflow obstruction
}

\author{
Roosevelt Bryant III, MD
}

\footnotetext{
From the Division of Cardiovascular Surgery, The Heart Institute, Cincinnati Children's Hospital Medical Center, Cincinnati, Ohio.

Disclosures: Author has nothing to disclose with regard to commercial support.

Received for publication Oct 4, 2016; accepted for publication Oct 4, 2016; available ahead of print Nov 17, 2016 Address for reprints: Roosevelt Bryant III, MD, Pediatric Heart Transplant Program, Cincinnati Children's Hospital Medical Center, The University of Cincinnati College of Medicine, 3333 Burnet Ave, MLC 2004, Cincinnati, OH 45229 (E-mail: Roosevelt.BryantIII@cchmc.org).

J Thorac Cardiovasc Surg 2017;153:e31-2

$0022-5223 / \$ 36.00$

Copyright $\odot 2016$ Published by Elsevier Inc. on behalf of The American Association for Thoracic Surgery http://dx.doi.org/10.1016/j.jtcvs.2016.10.027
}

More than 30 years ago, Cochrane and associates ${ }^{1}$ proposed a novel pathology for left ventricular inflow obstruction: a dilated coronary sinus associated with a persistent left superior vena cava (LSVC). As the clinical experience with this entity has grown, its association with other left heart obstructive lesions has become better appreciated, and the surgical therapies have been modified. In 1999, Agnoletti and colleagues ${ }^{2}$ initially described the association between left heart obstructive lesions and a persistent (LSVC) with a dilated coronary sinus. In their report, $39 \%$ of patients with a persistent LSVC versus $7.8 \%$ of those without had other left heart obstructive lesions. Dibardino and associates ${ }^{3}$ added to the clinical recognition of this association in 2004. They described a series of 6 patients with a persistent LSVC and dilated coronary sinus who were found to have other left heart obstructive lesions. The other left heart lesions included a supravalvular mitral ring $(\mathrm{n}=2)$, a parachute mitral valve $(\mathrm{n}=1)$, mitral annular hypoplasia $(\mathrm{n}=1)$, and hypoplasia of the left ventricle. Two patients in this series also had coarctation of the aorta.

The surgical therapy for a dilated coronary sinus causing left ventricular inflow obstruction has underdone some evolution. In the 1994 report from Cochrane and associates, ${ }^{1}$ the proposed surgical management was coronary sinus reduction with resection of a segment of the wall. All patients in the Cochrane ${ }^{1}$ and Dibardino ${ }^{3}$ series underwent coronary sinus reduction angioplasty. Coronary sinus reduction has become the foundation for subsequent surgical modifications. In some cases, the LSVC can simply be ligated in patients with a bridging innominate vein to a right superior vena cava; however, patients with a persistent LSVC and a dilated coronary sinus often do not have a bridging innominate vein. In the absence of a bridging innominate vein, Vargas and associates ${ }^{4}$ proposed a modification of the coronary sinus reduction. They proposed a more extensive reduction coronary sinus angioplasty along its entire length in the left atrium, with

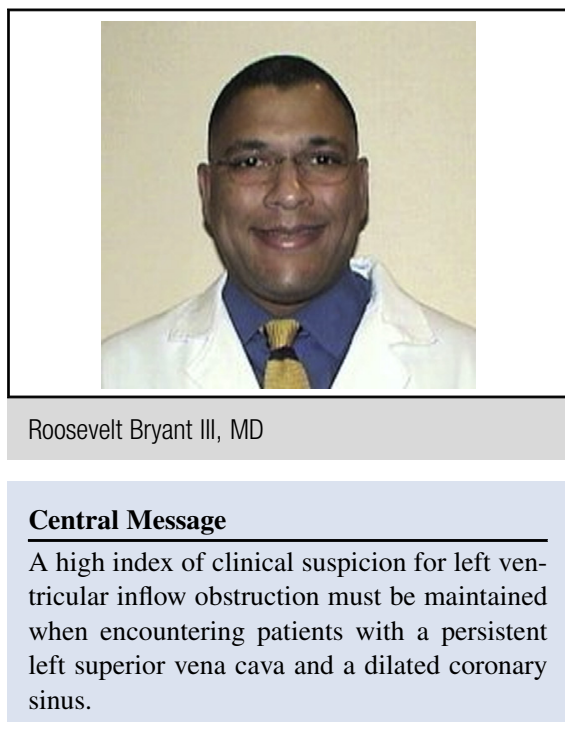

See Article page e27.

reimplantation of the LSVC into the right atrial appendage. This was not done in the case reported on in this issue of the Journal by Gowda and colleagues. ${ }^{5}$ And although the outcome was good in the case of Vargas and associates, ${ }^{4}$ there was a residual mean gradient of $4 \mathrm{~mm}$ $\mathrm{Hg}$ across the mitral valve. The central message from the Vargas experience was that in the absence of a right superior vena cava and bridging innominate vein, there is a need for a more extensive coronary sinus reduction angioplasty to obtain effective complete relief of the left ventricular inflow obstruction.

The report by Gowda and colleagues ${ }^{5}$ reaffirms what the literature to this point has told us. That is, in patients with a persistent LSVC, absent innominate vein and right superior vena cava, and other left heart obstructive lesions, a high index of suspicion for left ventricular inflow obstruction related to a dilated coronary sinus is warranted. Intraoperative inspection of the coronary sinus-mitral valve relationship must be meticulously assessed, and the surgical approach may need to be modified. With appropriate surgical intervention, satisfactory outcome should be expected.

\section{References}

1. Cochrane AD, Marath A, Mee RB. Can a dilated coronary sinus produce left ventricular inflow obstruction? An unrecognized clinical entity. Ann Thorac Surg. 1994;58:1114-6. 
2. Agnoleti G, Annecchino F, Preda L, Borghi A. Persistence of the left superior caval vein: can it potentiate obstructive lesions of the left ventricle? Cardiol Young. 1999; 9:285-90.

3. Dibardino DJ, Fraser CD Jr, Dickerson HA, Heinle JS, McKenzie ED, Kung G. Left ventricular inflow obstruction associated with persistent left superior vena cava and dilated coronary sinus. J Thorac Cardiovasc Surg. 2004;127:959-62.
4. Vargas FJ, Rozenbaum J, Lopez R, Granja J, De Dios A, Zarlenga B, et al. Surgical approach to left ventricular inflow obstruction due to a dilated coronary sinus. Ann Thorac Surg. 2006;82:191-6.

5. Gowda D, Praveen CH, Sirohi A, Desai N. An unusual case of giant coronary sinus causing left ventricular inflow obstruction. J Thorac Cardiovasc Surg. 2017;153: e27-9. 